Brit. J. industr. Med., 1955, 12, 153.

\title{
PROTECTION AGAINST $X$ RAYS AND GAMMA RAYS IN THE INDUSTRIAL FIELD *
}

\author{
BY \\ W. BINKS \\ From the Radiological Protection Service (Ministry of Health and Medical Research Council)
}

The purpose of this contribution is to present a summary of available information and procedures regarding the protection of radiological workers against $x$ rays and gamma rays emitted by sources external to the body. In this way it is hoped to assist those responsible for the planning and designing of industrial radiological departments to provide adequate and, at the same time, economical protective measures.

\section{Maximum Permissible Doses of Radiation}

Although it may be assumed that any ionizing radiation above the " natural " level to which human beings are always subjected may be deleterious, evidence on radiation effects has indicated that, for each type of radiation, it is possible to choose a practical average level to which a radiological worker may be exposed, with negligible risk, throughout his working life. The average level so chosen is referred to as the " maximum permissible weekly dose."

According to the recommendations of the International Commission on Radiological Units (1954), " absorbed dose"-or amount of energy imparted to matter by ionizing particles per unit mass of irradiated material at the place of interest-shall be expressed in terms of the " $\mathrm{rad}$ ", which has the value of 100 ergs per gram. But for $x$ rays and gamma rays of quantum energy up to $3 \mathrm{MeV}$, the röntgen (r) may be used. Accepting this proposal, the International Commission on Radiological Protection, 1954 (I.C.R.P.), recommends that the basic maximum permissible dose (m.p.d.) for exposure of the whole body to radiation expressible in röntgens is $\mathbf{0 . 3}$ per week in the blood-forming organs, eyes, and gonads. For partial irradiation of the body (for example, hands and forearms, feet and ankles, head and neck), the corresponding dose is $1.5 \mathrm{r}$ per week in the skin, provided that, in the

\footnotetext{
* Because space in the Journal is limited this paper has had to be cut and many of the illustrations, originally presented as slides, omitted.-ED.
}

case of the head and neck, the dose-rate in the lens of the eye does not exceed $0.3 \mathrm{r}$ per week. On the basis of practical considerations, the m.p.d. for whole-body exposure may be modified to $0.3 \mathrm{r}$ per week in air.

\section{Physical Factors in Protective Schemes}

First, it is necessary to know the total weekly dose of radiation which would be received at the point of interest in the absence of any absorbing shield. The radiation may be that received directly from an $x$-ray tube or from a gamma-ray emitting radioisotope, or indirectly from an irradiated specimen which scatters some of the radiation falling upon it. Secondly, a knowledge of the efficacy of various materials in absorbing radiations of different types is required. From a combination of these factors it is possible to assess the thickness of the absorbing shield required in any set of circumstances to reduce the dose at the point of interest to less than the maximum permissible level. In making such an assessment, allowance should be made for the maximum anticipated weekly dose.

$X$-ray tubes, and some radioisotope containers, intended for radiographic purposes can, by design, emit a useful beam only within a restricted cone. Accordingly, it is not justifiable on economic grounds to provide shielding on every wall of a room which is to house an $x$-ray tube or radiographic unit of the type mentioned, on the assumption that the useful beam could be directed at every wall for the entire working week, that the source is emitting radiation continuously at its maximum level (for example, that the $x$-ray tube is operated continuously at its maximum voltage and maximum rated current), and that the workers to be protected are going to be stationed in close proximity to the walls in question for their entire working lives. It should be possible to design protective arrangements more economically by taking a more realistic picture of the operating conditions, at the same time 
allowing a margin of safety for future development and expansion of the work, since it is often less expensive to incorporate additional protection during the initial building of a department than at a later stage.

Radiation from $\boldsymbol{X}$-ray Tubes.-Manufacturers of $x$-ray tubes usually specify the radiation dose-rate (in $\mathrm{r} / \mathrm{min}$.) at 1 metre from the tubes under full loading. In a previous publication the author has given figures as a rough guide to such dose-rates for constant potential excitation (Binks, 1943). Doserates at other distances can be calculated, as these decrease as the square of the distance from the $x$-ray target.

Radiation from Gamma-ray Emitting Isotopes.The dose-rates from radioisotopes which emit gamma rays are often expressed in terms of the so-called " $\mathrm{K}$ factor" (r/hr. per $\mathrm{mC}$ at $1 \mathrm{~cm}$. distance). The activity of any isotope will be specified in curies by the suppliers, so that the total gamma-ray output in $\mathrm{r} / \mathrm{hr}$. at $1 \mathrm{~cm}$. distance can be calculated. Table 1 lists the $\mathrm{K}$ factors of a few of the radioisotopes of potential use in industrial radiography. Again, the inverse square law can be applied to determine the dose-rates at other distances.

Allowable Transmission through Protective Shields. -Calculations are given below.

For Direct $X$ rays or Gamma Rays.-The maximum transmission which is allowable for any protective shield, if it is to reduce the direct $x$ rays or gamma rays to below the m.p.d., may be calculated in the following manner.

Let $\quad R=$ dose-rate (in $\mathrm{r} / \mathrm{min}$.) at 1 metre from radiation source.

where $\mathrm{R}=(\mathrm{r} / \mathrm{min} . / \mathrm{mA}$ at 1 metre) $\times$ (tube current in $\mathrm{mA})$ for $x$ rays

or $\frac{(\mathrm{r} / \mathrm{hr} . / \mathrm{mC} \text { at } 1 \mathrm{~cm} .) \times(\text { no. of } \mathrm{mC})}{60 \times 10^{4}}$

for gamma rays

$\mathrm{t}=$ maximum time (in minutes) of radiation exposure of worker per week.

$D=$ distance (in metres) from radiation source to nearest point to be occupied by worker.

$\therefore \quad$ Weekly dose at worker's position $=\frac{\mathbf{R t}}{\mathbf{D}^{2}}$ röntgens .

Percentage transmission of protective shield to reduce dose-rate to $0.3 \mathrm{r} /$ week (in free air) $=30 \frac{\mathrm{D}^{2}}{\mathrm{Rt}} \ldots$

For Scattered $X$ Rays or Gamma Rays.-A similar procedure may be followed for scattered radiation. In this respect it should be mentioned that the amount of scattered radiation received at
TABLE 1

K FACTORS OF RADIOISOTOPES OF POTENTIAL USE IN INDUSTRIAL RADIOGRAPHY

\begin{tabular}{|c|c|c|c|}
\hline Isotope & Half-life & $\begin{array}{l}\text { Energy } \\
(\mathrm{MeV})\end{array}$ & $\begin{array}{c}\mathrm{K} \text { factor } \\
\text { (r/hr. per } \mathrm{mC} \\
\text { at } 1 \mathrm{~cm} .)\end{array}$ \\
\hline $\begin{array}{l}\mathrm{Co}^{60} \\
\mathrm{Cs}^{137} \\
\mathrm{Tm}^{170} \\
\mathrm{Ta}^{182} \\
\mathrm{Ba}^{187}\end{array}$ & $\begin{array}{r}5 \cdot 3 \text { years } \\
33 \text { years } \\
129 \text { days } \\
120 \text { days }\end{array}$ & $\begin{array}{c}1 \cdot 17,1.33 \\
0.669 \\
0.084(24 \%) \\
\text { Complex spectrum ; } \\
0.05-1.2\end{array}$ & $\begin{array}{c}13 \cdot 5 \\
3 \cdot 9 \\
0 \cdot 08 \\
6 \cdot 1\end{array}$ \\
\hline $\mathrm{Ra}^{226}+$ daughter & $\begin{array}{r}75 \text { days } \\
1590 \text { years }\end{array}$ & $\begin{array}{l}0 \cdot 13-0 \cdot 61 \\
0 \cdot 24-2 \cdot 2\end{array}$ & $\begin{array}{l}2 \cdot 7 \\
8 \cdot 3\end{array}$ \\
\hline
\end{tabular}

any point in the neighbourhood of a scattering object is (1) roughly proportional to the area of irradiation of the object, and (2) inversely proportional to the square of the distance from the object.

If $\quad \mathbf{R}=$ dose-rate (in $\mathrm{r} / \mathrm{min}$.) at 1 metre from radiation source.

$\mathrm{t}=$ maximum time (in minutes) of radiation exposure of worker per week.

$\mathrm{D}=$ distance (in metres) from radiation source to surface of irradiated object.

$a=$ area (in sq. $\mathrm{cm}$.) of field of irradiation of object.

$\mathrm{d}=$ distance (in metres) from scattering body to nearest point to be occupied by worker.

$\mathrm{s}=$ percentage scatter, at 1 metre from exposed object, in direction of working site, per $100 \mathrm{sq} . \mathrm{cm}$. of field of irradiation.

$\therefore$ Weekly dose of scattered radiation at worker's position

$=\frac{\mathrm{Rt}}{\mathrm{D}^{2}} \times \frac{\mathrm{s}}{100 \mathrm{~d}^{2}} \times \frac{\mathrm{a}}{100}$ röntgens $\ldots$

Percentage transmission of protective shield to reduce dose-rate to $0.3 \mathrm{r} /$ week (in free air)

$$
=3 \times 10^{5} \frac{\mathrm{D}^{2} \mathrm{~d}^{2}}{\mathrm{Rtsa}} \cdots
$$

At a later stage in the paper data will be presented on the amount of scattering from different materials exposed to different types of radiation.

Absorption of Radiation.-It would be well, before proceeding to examine the experimental observations concerning the absorption of $x$ rays and gamma rays, to attempt a survey of the theoretical background, as this will help to appreciate the significance of the experimental data.

A photon of $x$ rays or gamma rays can interact with an atom in four ways: (1) With the atomic electrons ; (2) with the protons and neutrons in the nucleus; (3) with the electric field surrounding the electrically charged nuclei and electrons; and, (4) with any meson field surrounding the protons and neutrons.

The net result of any of these interactions is that the photon may surrender all its energy, or only a portion, or indeed none at all. Of these 12 possi- 
bilities, some have not yet been observed, while some occur much less frequently than others.

In the main, only three processes need be considered for our present purposes. These are : (1) The photoelectric effect, in which the photon, whose energy must be greater than that of the binding energy of the atomic electron involved, transfers all its energy, in excess of this binding energy, to the electron, which is ejected from the atom ; (2) the Compton effect, in which the photon interacts with an atomic electron, and transfers only part of its energy during the process, which results in the ejection of the electron and the survival of the photon, which is degraded in energy and has its direction of motion changed ; (3) pair-production effect, in which the photon, whose energy must be greater than $1.02 \mathrm{MeV}$, interacts with the electric field surrounding the nucleus and atomic electrons, and surrenders the whole of its energy, leading to the creation of an electron and a positron (electron pair).

Mention should be made of a fourth processRayleigh scattering-in which the photon interacts with the protons and neutrons in the nucleus. But since this accounts for only a few per cent. of the total absorption for $100 \mathrm{kV} x$ rays produced by the three main processes referred to, and becomes negligible for $x$ rays above $300 \mathrm{kV}$ for light elements and above $1 \mathrm{MV}$ for heavy elements such as lead, no allowance for it will be made in the present study.

Photoelectric Effect.-As regards the photoelectric effect, Heitler (1936) derived a theoretical formula for the photoelectric absorption effect in the $\mathrm{K}$ shell of the atom. The formula does not hold for photons of energy in the relativistic range and it is grossly inaccurate for photons of energy similar to the binding energy of the electron in the K-shell. A correction factor, $f(\varepsilon)$, for the latter inaccuracy has been worked out by Stobbe (1930). From an examination of the experimental data on photoelectric absorption, Binks (1954) has shown that the following empirical relationship holds for the absorption of photons up to $500 \mathrm{keV}$ in all elements $\mathrm{e}^{\tau}=4.47 \times 10^{-27} \cdot \mathrm{Z}^{4} \cdot \lambda^{3 \cdot 3} \cdot \mathrm{f}(\varepsilon) \ldots$ (5)

For the relativistic range of photon energies (that is, much greater than $500 \mathrm{keV}$ ) a theoretical formula derived by Hall $(1934,1936)$ is believed to be valid.

It should be added that, in the photoelectric process, there is a " side-effect", in that the ejection of an electron is followed by the emission of a photon of characteristic $x$ rays.

Compton Effect.-This process will be examined in so far as it may appear to the observer or "detector". The initial photon, which is assumed to be proceeding in the direction of the detector, can be regarded as surrendering all its energy to an absorber placed in its path. This energy reappears in the form of an electron and of a degraded photon. As the latter will proceed in a different direction from that of the initial photon it will now miss the detector. In other words, it appears to the detector that all the energy of the incident photon has been lost. Such will be the case with a " narrow-beam " of photons, since the degraded photons will be scattered out of the primary beam. If, however, there is a " broad-beam " of primary photons, some of which are not proceeding towards the detecting point, the detector will receive some of the degraded photons. Thus, to the detector it would appear that less energy has been removed by an absorber under " broad-beam" conditions than under " narrowbeam " conditions of irradiation.

The total Compton absorption per electron, $\mathrm{e}^{\sigma}$, may be split into two components, the first, $e^{\sigma_{a}}$, relating to the energy removed by the ejected electron, and the second, ${ }_{e} \sigma_{s}$, relating to the energy taken by the modified photon. In narrow beams the effective absorption will be $e_{e} \sigma_{a}+e_{e} \sigma_{s}$; in broad beams it will be ${ }_{e} \sigma_{a}+f_{\cdot e} \sigma_{s}$, where $f_{\cdot e} \sigma_{s}$ represents a fraction of this component, and depends on the size of the irradiated field, the material and thickness of the absorbing layer, and the positions of the radiation source and detector relative to the absorber.

The Compton linear absorption coefficient for any element is derived from the absorption coefficient per electron by multiplying by the electron density of that element. There should, therefore, be more scattered radiation generated in, say, a lead absorber than in absorbers of the same thickness composed of light elements. There is, however, a counter-effect. As will be seen from formula (5), dealing with the photoelectric effect, absorption per electron due to this process increases as the fourth power of the atomic number and as the 3.3 power of the wave-length. Accordingly, the degraded scattered photons, which are of longer wave-length than the initial photons, will, whatever the absorbing element, undergo greater photoelectric absorption than the initial photons and will, furthermore, be subjected to very much higher photoelectric absorption in an element of high atomic number, such as lead, than in elements of low atomic number.

Pair-production Effect.-The first theoretical predictions (Bethe and Heitler, 1934) indicated that the pair-production absorption coefficient per electron should be proportional to the atomic number $\mathbf{Z}$ of the element. Later it was seen that the proportionality factor is nearer $Z+1$. 
Again, there is a side-effect which should be noted. The positron of an electron-pair is quickly " annihilated" for, when it encounters an atomic electron, the two combine and release energy of the order of $1.02 \mathrm{MeV}$ or more, generally in the form of two photons.

Finally, it should be mentioned that, in all the processes here considered, it is possible for the electrons (or positrons), which are emitted following the interaction of the photon with the atom, to re-radiate energy as they are slowed down in the absorbing material. This type of radiation is known as Bremsstrahlung.

Total Absorption Coefficient.-The total absorption coefficient (expressed as the electronic, or atomic, or linear, or mass coefficient) is the sum of the photoelectric, Compton, and pair-production coefficients. Applying these coefficients, calculations have been made of the absorption, in lead and other materials, of $x$ rays and gamma rays under " narrowbeam" conditions (Kaye and Binks, 1940) and of gamma rays under some selected "broad-beam" conditions (Fano 1949, 1953 ; Fano, Hurwitz, and Spencer, 1950). The calculated absorption data are in close agreement with the experimental results.

$X$-Ray and Gamma-Ray Absorption Data.Certain data are now available.

$X$ rays.-Experimental transmission curves in lead are now available for $x$ rays excited at voltages between 50 and $2000 \mathrm{kV}$, for "broad-beam" conditions. For voltages between 50 and $200 \mathrm{kV}$, transmission curves are given in an earlier paper by the author (Binks, 1943), and relate to beams filtered through an $x$-ray tube window equivalent in absorption to $0.07 \mathrm{~mm}$. Cu. The curves for 200 to $300 \mathrm{kV} x$ rays, appearing in Fig. 1, are also from observations made by the author for appropriately

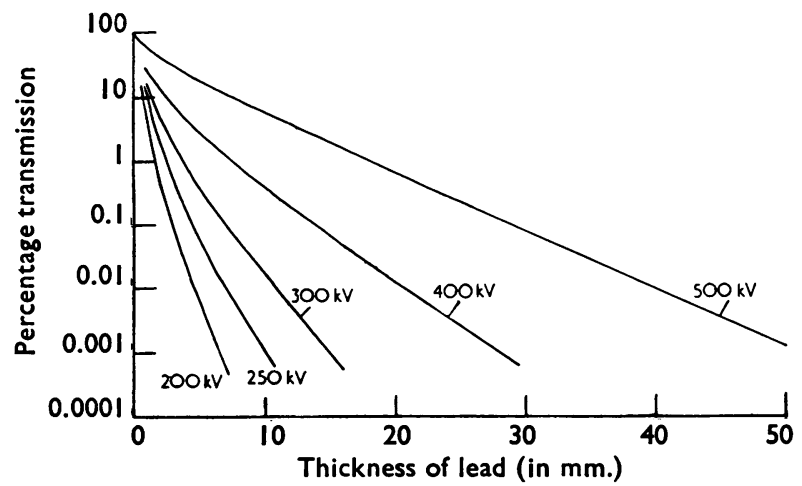

Fig. 1.-Transmission curves in lead for $x$ rays excited at various constant voltages between $200 \mathrm{kV}$. and $500 \mathrm{kV}$.

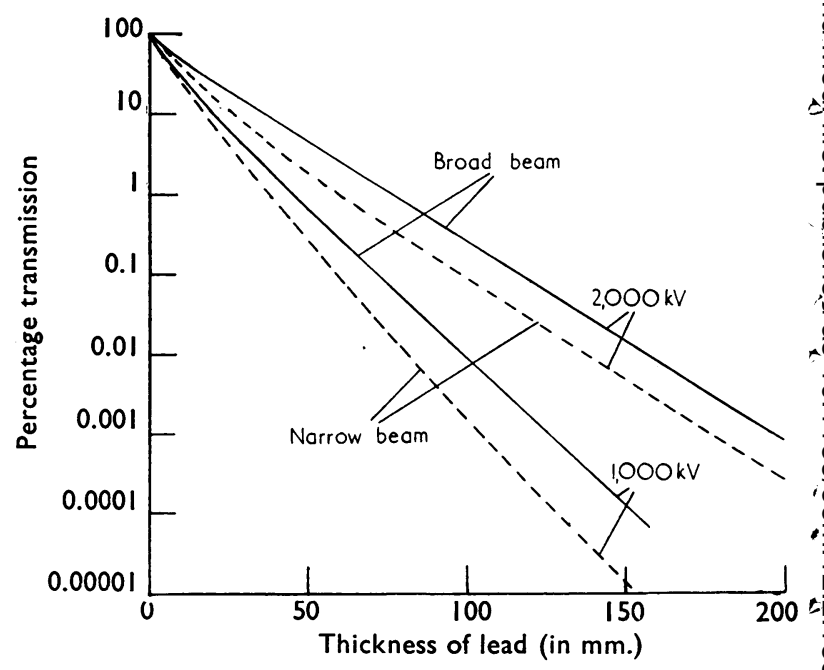

FIG. 2.-Transmission curves in lead for broad and narrow beams of $x$ rays excited at constant voltages of $1000 \mathrm{kV}$. and $2000 \mathrm{kV}$.

heavier degrees of filtration, while the $500 \mathrm{kV}$ curve is taken from the results of Wyckoff, Kennedy, and Bradford (1948). The $400 \mathrm{kV}$ curve is one deduced by interpolation. In Fig. 2 is a broad-beam curve determined experimentally (Wyckoff, and his colleagues, 1948) for $1000 \mathrm{kV} x$ rays which had been passed through a rather complex initial filter, composed of $2.8 \mathrm{~mm}$. tungsten, $2.8 \mathrm{~mm}$. copper, $2.1 \mathrm{~mm}$. brass, and $18.7 \mathrm{~mm}$. water. There is, also, a broad-beam curve for $2000 \mathrm{kV} x$ rays filtered through a composite window equivalent to $6.8 \mathrm{~mm}$. lead (Evans, Granke, Wright, and Trump, 1952)*. In the same figure are plotted curves based on calculations which the author has made for narrow beams of 1000 and $2000 \mathrm{kV} x$ rays, initially filtered through the respective filters mentioned above. The ratio of the broad-beam transmission (direct plus scattered photons) to the narrow-beam transmission (direct photons only) is called the " dose build-up factor", which is due to scattered photons. The estimated build-up factors are given in Table 2. It will be clear from this evidence that protection measures against direct $x$-radiation must be based on broad-beam data, otherwise they may be inadequate.

For $x$ rays excited at voltages above $2 \mathrm{MV}$, there are no experimental values on broad-beam transmissions through lead. There are, however, data for concrete (Evans and others, 1952; Singer, Braestrup, and Wyckoff, 1946 ; Kirn and Kennedy, 1954).

* (Private communication). Curve deduced by Mr. E. E. Smith, National Physical Laboratory, from experimental observations of Evans, Granke, Wright and Trump. 
TABLE 2

DOSE BUILD-UP FACTORS FOR $X$ RAYS TRANSMITTED THROUGH LEAD

\begin{tabular}{c|c|c}
\hline \multirow{2}{*}{$\begin{array}{c}\text { Thickness of Lead } \\
(\mathrm{cm} .)\end{array}$} & \multicolumn{2}{|c}{ Dose Build-up Factors } \\
\cline { 2 - 3 } & $1000 \mathrm{kV} X$ Rays & $2000 \mathrm{kV} X$ Rays \\
\hline 0 & 1.0 & 1.0 \\
2 & 1.4 & 1.5 \\
4 & $2 \cdot 1$ & $2 \cdot 2$ \\
6 & 3.0 & 2.5 \\
8 & 4.0 & $2 \cdot 8$ \\
10 & 5.5 & $2 \cdot 8$ \\
12 & 6.9 & 2.9 \\
14 & 8.5 & 3.0 \\
16 & - & 3.0 \\
18 & - & 3.0 \\
\hline
\end{tabular}

Having estimated, by means of relationship (2) on p. 154, the maximum allowable percentage transmission through a protective shield to reduce the dose-rate of direct $x$ rays to below $0.3 \mathrm{r}$ per week, the thicknesses of lead which will transmit to this extent at known distances from $x$-ray sources of different energy can be read off from the given figures. In many cases, the designer of a radiological department will wish to translate the lead thicknesses into equivalent thicknesses of brick, concrete, or barium concrete (or plaster). Figures which will assist the translation, and which are based upon experimental work and new theoretical calculations. The growth of these factors with increasing thickness of absorber (expressed in terms of weight per unit area) in the path of the beam is illustrated in Fig. 3. These curves indicate that, for thicknesses up to about $70 \mathrm{lb}$./sq. $\mathrm{ft}$., the transmission of broad beams

TABLE 3

RELATION BETWEEN THICKNESS OF BRICK AND LEAD EQUIVALENT AT VARIOUS $X$-RAY QUALITIES (BROADBEAM CONDITIONS)

\begin{tabular}{|c|c|c|c|c|c|c|c|c|}
\hline \multirow{2}{*}{$\begin{array}{l}\text { Thickness } \\
\text { of Brick* } \\
\text { (in inches) }\end{array}$} & \multicolumn{8}{|c|}{$\begin{array}{l}\text { Lead Equivalent (in mm.) for } X \text { rays Excited } \\
\text { at Following Kilovoltages }\end{array}$} \\
\hline & 50 & 75 & 100 & 150 & 200 & 250 & 300 & 400 \\
\hline $\begin{array}{l}4 \cdot 5 \\
9 \\
13 \cdot 5 \\
18\end{array}$ & $\begin{array}{l}0.7 \\
1.6 \\
-\end{array}$ & $\begin{array}{r}0 \cdot 9 \\
2 \cdot 0 \\
3 \cdot 2 \\
-\end{array}$ & $\begin{array}{l}1 \cdot 0 \\
2 \cdot 4 \\
3 \cdot 7 \\
\end{array}$ & $\begin{array}{l}0 \cdot 9 \\
2 \cdot 0 \\
3 \cdot 1 \\
4 \cdot 3\end{array}$ & $\begin{array}{l}0 \cdot 9 \\
2 \cdot 0 \\
3 \cdot 1 \\
4 \cdot 3\end{array}$ & $\begin{array}{l}1 \cdot 2 \\
2 \cdot 8 \\
4 \cdot 9 \\
7 \cdot 2\end{array}$ & $\begin{array}{c}1 \cdot 3 \\
3 \cdot 7 \\
6 \cdot 8 \\
10\end{array}$ & $\begin{array}{r}1 \cdot 5 \\
5 \cdot 6 \\
10 \cdot 3 \\
15 \cdot 2\end{array}$ \\
\hline
\end{tabular}

of radium gamma rays is much the same for all materials. That is to say, the "density law", which is applicable for all thicknesses of materials for narrow-beam conditions, applies here also over a very limited range. Above $70 \mathrm{lb} . / \mathrm{sq}$. ft., the scattering conditions depend on the atomic number of the absorber; the heavier the element, the smaller is the scattering.

TABLE 4

RELATION BETWEEN THICKNESS OF ORDINARY CONCRETE AND LEAD EQUIVALENT AT VARIOUS $X$-RAY QUALITIES (BROAD-BEAM CONDITIONS)

\begin{tabular}{|c|c|c|c|c|c|c|c|c|c|c|c|}
\hline \multirow{2}{*}{$\begin{array}{c}\text { Thickness of Concrete* } \\
\text { (in inches) }\end{array}$} & \multicolumn{11}{|c|}{ Lead Equivalent (in mm.) for $X$ rays Excited at Following Kilovoltages } \\
\hline & 50 & 75 & 100 & 150 & 200 & 250 & 300 & 400 & 500 & 1000 & 2000 \\
\hline $\begin{array}{r}2 \\
4 \\
6 \\
8 \\
10 \\
12 \\
14 \\
16 \\
18 \\
20 \\
24 \\
30 \\
36\end{array}$ & $\begin{array}{l}0.4 \\
0.9 \\
1.4 \\
2.0 \\
2.5 \\
3.1 \\
= \\
= \\
= \\
=\end{array}$ & $\begin{array}{l}0 \cdot 5 \\
1 \cdot 2 \\
2.0 \\
2 \cdot 8 \\
3 \cdot 6 \\
4 \cdot 3 \\
= \\
= \\
= \\
=\end{array}$ & $\begin{array}{l}0.6 \\
1.4 \\
2 \cdot 4 \\
3.4 \\
4.4 \\
5 \cdot 4 \\
= \\
= \\
= \\
= \\
-\end{array}$ & $\begin{array}{l}0 \cdot 5 \\
1 \cdot 2 \\
1.9 \\
2 \cdot 7 \\
3 \cdot 4 \\
4 \cdot 2 \\
5 \cdot 1 \\
= \\
= \\
= \\
=\end{array}$ & $\begin{array}{l}0.5 \\
1.2 \\
2.1 \\
2.9 \\
3.8 \\
4.7 \\
5.6 \\
= \\
= \\
= \\
=\end{array}$ & $\begin{array}{l}0.6 \\
1.7 \\
3.0 \\
4.4 \\
5.8 \\
7.3 \\
8.6 \\
= \\
= \\
= \\
=\end{array}$ & $\begin{array}{c}0 \cdot 8 \\
2 \cdot 2 \\
3 \cdot 8 \\
5 \cdot 8 \\
7 \cdot 9 \\
10 \\
12 \\
= \\
= \\
= \\
-\end{array}$ & $\begin{array}{l}1 \cdot 1 \\
3 \cdot 0 \\
5 \cdot 4 \\
8 \cdot 5 \\
11 \\
14 \\
18 \\
21 \\
24 \\
= \\
= \\
-\end{array}$ & $\begin{array}{c}1 \cdot 6 \\
3 \cdot 9 \\
7 \cdot 1 \\
11 \\
15 \\
19 \\
24 \\
28 \\
33 \\
37 \\
46 \\
60 \\
-\end{array}$ & $\begin{array}{c}4 \cdot 0 \\
8 \cdot 6 \\
14 \\
21 \\
29 \\
37 \\
45 \\
54 \\
62 \\
71 \\
88 \\
112 \\
138\end{array}$ & $\begin{array}{r}6 \\
13 \\
22 \\
31 \\
40 \\
49 \\
58 \\
67 \\
76 \\
85 \\
103 \\
130 \\
159\end{array}$ \\
\hline
\end{tabular}

${ }^{*}$ Density $2 \cdot 2$ g./cc.

available information, are presented in Tables 3 , 4 , and 5.

Gamma Rays.-Information concerning the absorption of the gamma rays of radium, cobalt 60 , caesium 137, and iridium 192 in lead and other materials is gradually accumulating.

As regards the absorption of radium gamma rays in lead, the data are summarized in a previous paper by the author (Binks, 1954).

Dose build-up factors have been deduced from these data. Similar dose build-up factors have been deduced for steel and brick from the author's earlier
TABLE 5

RELATION BETWEEN THICKNESS OF BARIUM CONCRETE OR PLASTER AND LEAD EQUIVALENT AT VARIOUS $X$-RAY QUALITIES (BROAD-BEAM CONDITIONS)

\begin{tabular}{|c|c|c|c|c|c|c|c|c|}
\hline \multirow{2}{*}{$\begin{array}{l}\text { Thickness } \\
\text { of Barium } \\
\text { Concrete } \\
\text { or Plaster* } \\
\text { (in inches) }\end{array}$} & \multicolumn{8}{|c|}{$\begin{array}{l}\text { Lead Equivalent (in mm.) for } X \text { rays Excited } \\
\text { at Following Kilovoltages }\end{array}$} \\
\hline & 50 & 75 & 100 & 150 & 200 & 250 & 300 & 400 \\
\hline $\begin{array}{r}0.5 \\
1 \\
2 \\
3 \\
4\end{array}$ & $\begin{array}{l}1 \cdot 2 \\
2 \cdot 3 \\
\text { 二 } \\
-\end{array}$ & $\begin{array}{l}1 \cdot 8 \\
3 \cdot 3 \\
\text { 二 } \\
-\end{array}$ & $\begin{array}{l}2 \cdot 2 \\
4 \cdot 1 \\
= \\
-\end{array}$ & $\begin{array}{l}1 \cdot 2 \\
2 \cdot 3 \\
4 \cdot 3 \\
5.9 \\
-\end{array}$ & $\begin{array}{l}0.9 \\
1.8 \\
3.4 \\
5 \cdot 1 \\
6.9\end{array}$ & $\begin{array}{l}0.8 \\
1.7 \\
3.7 \\
5.8 \\
7.9\end{array}$ & $\begin{array}{l}0 \cdot 8 \\
1.9 \\
4.0 \\
6.3 \\
8.6\end{array}$ & $\begin{array}{l}0.9 \\
2.1 \\
4.5 \\
7.0 \\
9.6\end{array}$ \\
\hline
\end{tabular}

*Density $3 \cdot 2$ g./cc. 


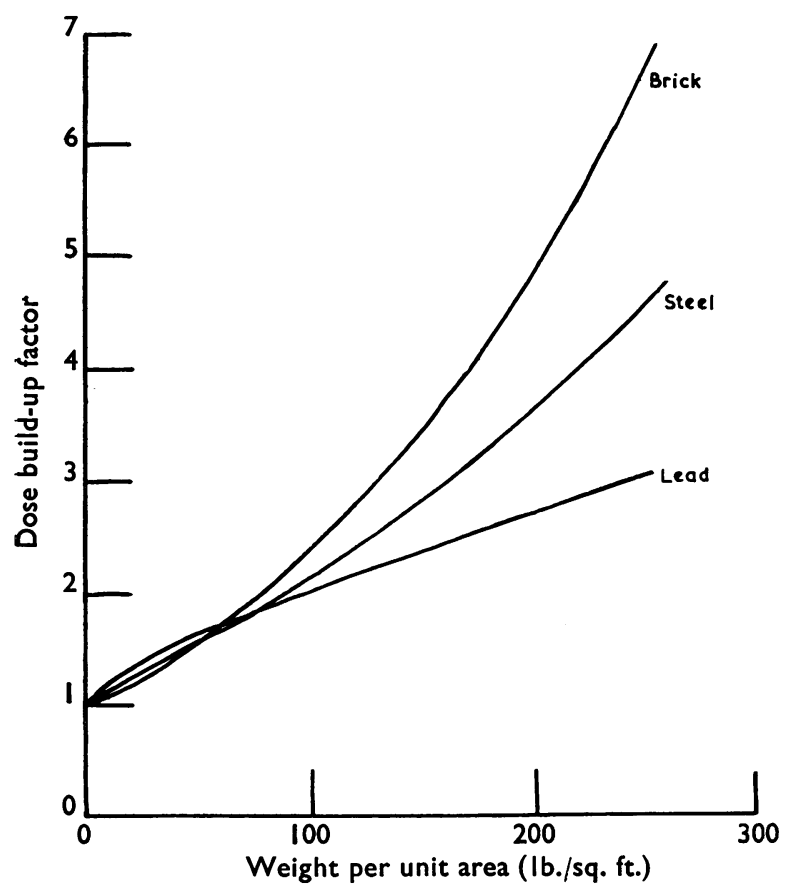

Fig. 3.-Dose build-up factors for radium gamma rays in lead, steel and brick.

Further data on the transmission through lead, steel, and concrete of broad beams of gamma rays from radium, cobalt 60 , and caesium 137 are given in Handbook 54 issued by the National Bureau of Standards in September, 1954. On the basis of the above can be deduced the thicknesses of protective shields of various materials required, at known distances from different gamma-ray sources, to reduce the dose-rate for direct radiation below $0 \cdot 3 \mathrm{r} /$ week.

\section{Oblique Transmission of High-energy Radiation through Walls}

Considerable errors may arise from assuming, as has been done in the past, that the transmission of a high-energy beam of $x$ rays or gamma rays obliquely through a shield is the same as for a beam passing normally through a shield of thickness equal to the slant distance in the oblique case. Measurements have been made (Kirn, Kennedy, and Wyckoff, 1954) of the oblique transmission, through lead and concrete, of the gamma rays from cobalt 60, caesium 137, and gold 198. The study reveals, particularly in the case of concrete, that the radiation transmitted along an oblique path is greater than that for normal incidence.

\section{Scattered Radiation}

Hitherto our efforts have been directed mainly towards the consideration of protective measures against direct beams of $x$ rays and gamma rays. Scattered radiation has entered into these considerations, but only in so far as it is mixed with the direct beam. It is now proposed to deal, in more detail, with scattered radiation only and with the measures which are desirable to afford protection against it. Most of the measurements which have been made in the past have been concerned with the scattering in various directions from a patient, or " phantom" of wax or wood, of $x$ rays excited at voltages between 50 and $200 \mathrm{kV}$. The results obtained have differed considerably. This would seem to be due to the fact that, if the beam falling on a patient passes very close to the side of the patient nearest the detector, much of the scattered radiation escapes from the body without re-absorption. On the other hand, if there is an appreciable distance between the edge of the beam and the edge of the patient, the softer scattered radiation may be partially, if not wholly, absorbed before it can get out of the patient. Such a spread of results (Binks, 1943 ; Wyckoff and Taylor, 1952) is portrayed in part of Fig. 4 in which the values of the percentage scattering (s) per $100 \mathrm{sq} . \mathrm{cm}$. of field at 1 metre to the side of the scattering body are plotted against the $x$-ray energy. In this sense, "side-scattering" is taken to mean the scattering in a direction approximately at right angles to the direction of the primary beam. "Back-scattering" means the scattering in a direction opposite to that of the primary beam. The point plotted at $300 \mathrm{kV}$ for concrete was obtained by the author; that at $1000 \mathrm{kV}$ is by Braestrup and Wyckoff (1948), that at $2000 \mathrm{kV}$ has been deduced from observations

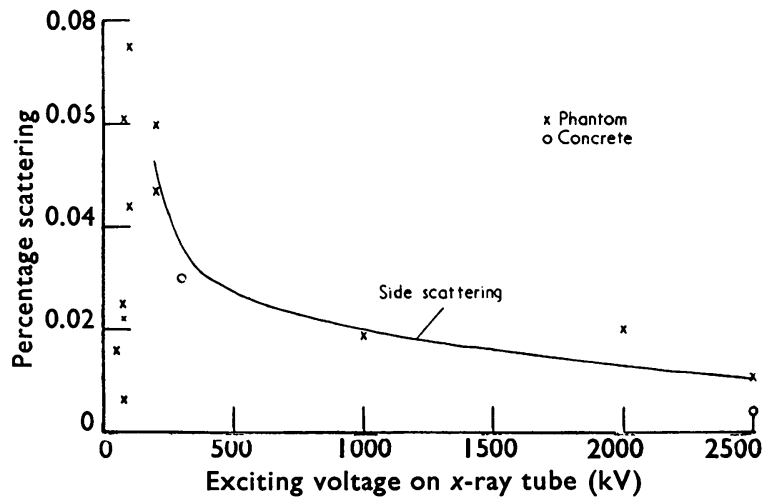

FIG. 4.-Percentage scattering per $100 \mathrm{sq}$. cm. of field at 1 metre from scattering body. 
reported by Wilson and Perry (1952), whilst those at $2500 \mathrm{kV}$ have been derived by the author from measurements by Dixon, Garrett, and Morrison (1952) with cobalt 60 gamma rays by expressing the energy in terms of the equivalent continuous $x$-ray spectrum. If the spread of results at 50 to $100 \mathrm{kV}$ is ignored, and the maximum scattering which is likely to occur is taken into account, it would seem that the degree of side-scattering decreases with increasing energy of the primary radiation. This would be in accord with theoretical predictions.

In the few observations which have been made, back-scattering seems to be about three times greater than side-scattering; also, scattering from steel is three times less than from concrete. It is hoped that this information will enable reasonably safe estimates to be made of the maximum allowable percentage transmissions of shields intended to provide protection against scattered radiation (relationship (4) ). At the same time it must be stressed that much more work is necessary in this field in order to unravel a complex state of affairs. In the low-voltage range $(70$ to $160 \mathrm{kV})$ Lindell (1954) has studied the energy spectrum of the $45^{\circ}$ scattering from such materials as lead, tin, zinc, copper, aluminium, and paraffin wax, and has shown how the scattered radiation depends upon the energy of the primary $x$-ray beam and upon the atomic number of the scatterer. On theoretical grounds, he has calculated the shape of the curve to be expected when the total intensity of scattered radiation from different elements is plotted against the atomic number. There is a rapid fall from light elements to iron and copper, after which there is a rise up to tin and a subsequent fall to lead. From iron up to the heaviest elements, the scatter consists largely of characteristic $x$ rays. Such characteristic radiation will have increasingly less importance at higher energies, for the protective shields required under these conditions will be able to absorb the characteristic rays much more easily than the Compton scatter.

Experimental data on the quality of cobalt 60 gamma-radiation, scattered at various angles from concrete, are provided in a paper by Dixon and his colleagues (1952). The scatter decreases in hardness as the angle between the direction of scatter and the primary beam increases. As regards absorption of the scattered radiation in concrete shields, roughly, the thickness required for $45^{\circ}$ scatter is two-thirds, and for $90^{\circ}$ scatter one-half, of the thickness required for the primary radiation.

\section{$X$-Ray Crystallographic Units}

The radiation hazards associated with the use of $x$-ray crystallographic equipment stem from the fact that (1) the inherent filter in the $x$-ray tube "window" is so thin that it transmits a much higher fraction of the rays, particularly of the soft components, than a tube designed for radiography, or therapy and (2) the distance between the tube and specimen is very short. The dose-rate in the beam is thus exceedingly high and may be of the order of $10,000 \mathrm{r} / \mathrm{min}$. or more. In addition the soft radiation is easily absorbed in the superficial layers of the skin. Serious, and sometimes permanent, damage to the skin can therefore result from even a few seconds' exposure in the direct beam. Accordingly, the equipment should be so designed that adjustments of specimens cannot be made without an automatic beam shutter coming into operation. A protective screen should also be provided which will absorb the intense direct beam behind the specimen in the camera.

Measures have also to be taken to deal with scattered radiation which usually originates at the front face of the camera where this is irradiated by the direct beam en route to the crystal. Most of this scatter can be intercepted by passing the primary beam along the axis of a cylindrical lead sheath placed between the window of the $x$-ray tube and the face of the camera. Scatter which escapes through this system or which originates from other parts of the equipment can be dealt with by erecting a lead screen near the unit, after all adjustments have been made. Because of the comparatively low voltages used to excite the $x$-ray beams for crystallography, sheet lead, 1 or 2 $\mathrm{mm}$. thick, proves quite effective as a shield.

\section{Other Possible Sources of $\boldsymbol{X}$ Rays}

Various types of apparatus not normally thought of as generators of $x$ rays are at times potentially hazardous in this respect. Amongst these may be mentioned transmitting valves, rectifying valves, cathode-ray tubes, and television sets, when these are operated at voltages in excess of about $5 \mathrm{kV}$.

The intensity of the radiation emitted depends, as with any orthodox $x$-ray tube, upon the exciting voltage, the tube current, and the thickness of the tube wall. The results of measurements made with low-voltage $x$ rays are given in Table 6. These refer to doses per 40 hours at 1 foot distance from a tube, with a tube current of $250 \mu \mathrm{A}$, which is of the order of the currents used in cathode-ray tubes in television sets. 
It will be seen that if a constructional or maintenance engineer has to carry out tests with cathoderay tubes in T.V. sets for any lengthy period he could under certain conditions receive dangerous doses. For example, a tube operating at $25 \mathrm{kV}$ and having a glass wall $5 \mathrm{~mm}$. thick could give the weekly permissible dose of $0.3 \mathrm{r}$ in about 15 minutes at 1 foot. If for test purposes, the tube current is reduced to, say, $50 \mu \mathrm{A}$, the m.p.d. would still be received in a little more than one hour. The radiation, even at $25 \mathrm{kV}$, is, however, very easily absorbed, and is reduced by a factor of about 10,000 by $0.1 \mathrm{~mm}$. lead or about $0.5 \mathrm{~mm}$. steel. Shielding of equipment of this nature is, therefore, a simple matter.

TABle 6

RESULTS OF MEASUREMENTS WITH LOW-VOLTAGE $X$ RAYS

\begin{tabular}{|c|c|c|}
\hline $\begin{array}{l}\text { Operating } \\
\text { Voltage } \\
(\mathrm{kV})\end{array}$ & $\begin{array}{l}\text { Thickness of } \\
\text { Tube Wall } \\
\text { (mm. glass) }\end{array}$ & $\begin{array}{l}\text { Dose in } \\
\text { r } 400 \text { Hours } \\
\text { at } 1 \text { Ft. }\end{array}$ \\
\hline $\begin{array}{l}6 \\
7 \\
8\end{array}$ & 0.5 & $\begin{array}{l}0.0008 \\
0.015 \\
0.3\end{array}$ \\
\hline $\begin{array}{r}7 \\
8 \\
9 \\
10\end{array}$ & 1 & $\begin{array}{l}0 \cdot 0003 \\
0.003 \\
0.03 \\
0 \cdot 3\end{array}$ \\
\hline $\begin{array}{l}10 \\
12 \\
14\end{array}$ & 2 & $\begin{array}{l}0.003 \\
0.08 \\
2 \cdot 5\end{array}$ \\
\hline $\begin{array}{l}14 \\
16 \\
18 \\
20 \\
25\end{array}$ & 5 & $\begin{array}{l}0.0015 \\
0.03 \\
0.3 \\
2.5 \\
50\end{array}$ \\
\hline $\begin{array}{l}20 \\
25\end{array}$ & 10 & $\begin{array}{l}0.004 \\
1\end{array}$ \\
\hline
\end{tabular}

Radiation Surveys and Personnel Tests

It is important that a radiation survey should be made of any new or modified radiological department to test the structural shielding. Routine operation of such a department should be deferred until it has been found to comply with the basic principles of radiation hygiene. This, however, in itself is not a sufficient guarantee of safety of the staff, since in many instances such safety depends as much upon adherence to particular techniques as upon the provision of structural shielding. For this reason it is necessary to check the actual doses of radiation which the radiological workers receive by means of suitable photographic films or ionization chambers which are carried on the body during the course of duty. These personnel tests may be continuous or periodic, depending upon the circumstances. Continuous monitoring may not be necessary if the officer-in-charge is satisfied that, in the light of the initial radiation survey and of occasional personnel tests, the radiation level can never exceed the permissible amount.

The photographic-film test provides the simplest, and, perhaps, least costly, means of checking personnel doses. The evaluation of the dose received by a film is based upon the degree of blackening produced by the radiation. Unfortunately, the blackening depends on the quality of the radiation as well as upon the quantity. If, therefore, as is usually the case, the radiation is of mixed quality, the method of assessing the dose must be such as to err on the side of over-estimating. The main claim of the method is that it affords a simple way of revealing cases of over-exposure or of borderline exposure. When such cases are found, an inspection of the department concerned should be made by means of ionization chambers whose response to radiation is independent, or nearly so, of the quality.

\section{The Radiological Protection Service}

The author is the Director of a comparatively new organization-the Radiological Protection Service-which has been set up jointly by the Ministry of Health and the Medical Research Council.

The functions of the organization are : (1) to assist the appropriate committees in this country responsible for the evaluation of maximum permissible levels and for the preparation of codes of practice for the safety of radiation workers; (2) to give advice on plans of new and modified radiological departments and to carry out radiation surveys ; (3) to provide personnel-monitoring services for both external and internal radiation; and (4) to carry out such research work as is necessary to supplement the efforts of other teams, both here and abroad, in acquiring the necessary information on which the satisfactory execution of the preceding three functions depends.

\section{Conclusion}

This survey will have served to show the present state of our knowledge regarding protection against $x$ rays and gamma rays, and to draw attention to the gaps in that knowledge. More research work is needed to improve our understanding of the effects of radiation on man and of the processes, particularly for high-energy radiation, of absorption and scattering, so that radiation protection measures may lead to "function with economy".

\section{REFERENCES}

Bethe, ${ }^{-H}$., and Heitler, W. (1934). Proc. roy. Soc. A., 146, 83. Binks,'WW. (1943). Brit. J. Radiol., 16, 49. 
Binks, W. (1954). Protection against Ionizing Radiations, ch. 14, p. 387 of Industrial Medicine and Hygiene, ed. E.R.A. Merewether, vol. 2. Butterworth, London.

Braestrup, C. B., and Wyckoff, H. O. (1948). Radiology, 51, 840

Dixon, W. R., Garrett, C., and Morrison, A. (1952). Nucleonics, 10, No.' 3, p. 42.

Evans, W. W., Granke, R. C., Wright, K. A., and Trump, J. G. (1952). Radiology, 58, 560 .

Fano, U. (1949). Phys. Rev., 76, 739.

(1953). National Bureau of Standards Report No. 2222, U.S.A.

- Hurwitz, H., and Spencer, L. V. (1950). Phys. Rev., 77, 425.

Hall, H. (1934). Ibid., 45, 620.

(1936). Rev. mod. Phys., 8, 395.

Heitler, W. (1936). Quantum Theory of Radiation. Clarendon Press, Oxford.

International Commission on Radiological Units (1954). Brit. J. Radiol., 27, 243.

International Commission on Radiological Protection (1954). Ibid.,

Kaye, G.' W. C., and Binks, W. (1940). Brit. J. Radiol., 13, 193.

Kirn, F. S., and Kennedy, R. J. (1954). See National Bureau of Standards Handbook No. 55 , U.S.A.

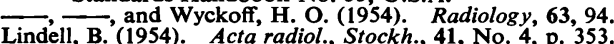

Singer, G., Braestrup, C. B., and Wyckoff, H. O. (1946). Amer. J. Roentgenol., 56, 771 .

Stobbe, M. (1930). Ann. Phys., Lpz., 5 ser., 1, 661.

Wilson, C. W., and Perry, B. J. (1952). Brit. J. Radiol., 25, 210.

Wyckoff, H. O., and Taylor, L. S. (1952). National Bureau of Standards Handbook No. 50 (issued in May, 1952), U.S.A. Nat. Bur. Stand., 41, 223 .

\section{Discussion}

Mr. G. M. MichIE (British Steel Castings Research Association) said that in many branches of industry today, mainly as a result of the availability of cheap radioactive isotopes, the extended application of radiographic inspection, notably of heavy steel castings, had taken place more quickly than suitably trained personnel had become available. In consequence managements had frequently to look for guidance in matters concerning both plant and protection to organizations outside their own companies, and to seek authoritative recommendations in connexion with proposed radiographic installations. As was well known, the Factory Department had given much guidance to many such companies, and had issued last year a useful pamphlet.

On the other hand, there was little doubt that what many firms required at the present time was something more concrete in the way of recommendations covering the precautions which they should observe if their personnel were to be adequately safeguarded, and an authoritative code of safe practice was a long-felt want.

The problem of providing adequate protection for personnel responsible for carrying out radiographic work with high intensity gamma-ray sources was undoubtedly the most difficult, since it was usually impracticable to adopt methods which would ensure that such personnel would never receive more than a doserate which, if maintained over the working week, would fall below the maximum permissible weekly dose. Thus, if the aim were to prevent operators from receiving at any time radiation intensities in excess of 7.5 milliröntgens per hour, isotope-handling rods would become unwieldy in length and containers so heavy that their positioning in awkward sites would prove a herculean task. A compromise must therefore be sought in which operators might receive higher dose-rates for short periods, to be compensated for in periods during which they were exposed to negligibly low intensity levels. In such circumstances it would be appreciated that the use of pocket ionization dose meters provided an invaluable safeguard, since they afforded a convenient method of keeping a continuous check on the radiation exposure received.

Mr. D. G. ARnotr (The London Hospital) suggested that the time was ripe for some legislation regarding the use of the materials in question which would lay down minimum standards of safety. Such legislation could be enacted under the Radioactive Substances Act. There was a great deal of difference between what was done under the auspices of the Atomic Energy Association and what was done in laboratories outside. In the first case there was an organization in which everybody was concerned with radiological hazards, but in an isotope laboratory these interests had to be shared with many non-ionizing interests, and it was difficult to enforce standards of protection in those circumstances. Those who worked with isotopes knew of many instances where abuses had crept in, and he would not be surprised to find that the radioactive effluent discharged from Harwell in a year was less radioactive than that discharged from some hospitals-not his own-in a week. Such abuses were difficult, once established, to get rid of, because it was never easy to get rid of a precedent, good or bad, once it had been established.

Mr. W. Binks supported Mr. Arnott's view. He would not necessarily maintain that it should be in the form of statutory regulations, because regulations normally had to be framed in such a way as to say that this must be done and that must not be done, and it was undesirable to hamstring the work which was going on by too detailed a specification. It appeared better to give guidance to workers through codes of practice. The first one was now nearly ready, dealing with the use of $x$ rays and radioisotopes in hospitals.

Mr. MichIE showed diagrams illustrating methods of calculating safe working distances and a plan for a safe exposure area. These are shown overleaf by courtes: of the British Steel Castings Research Association. 


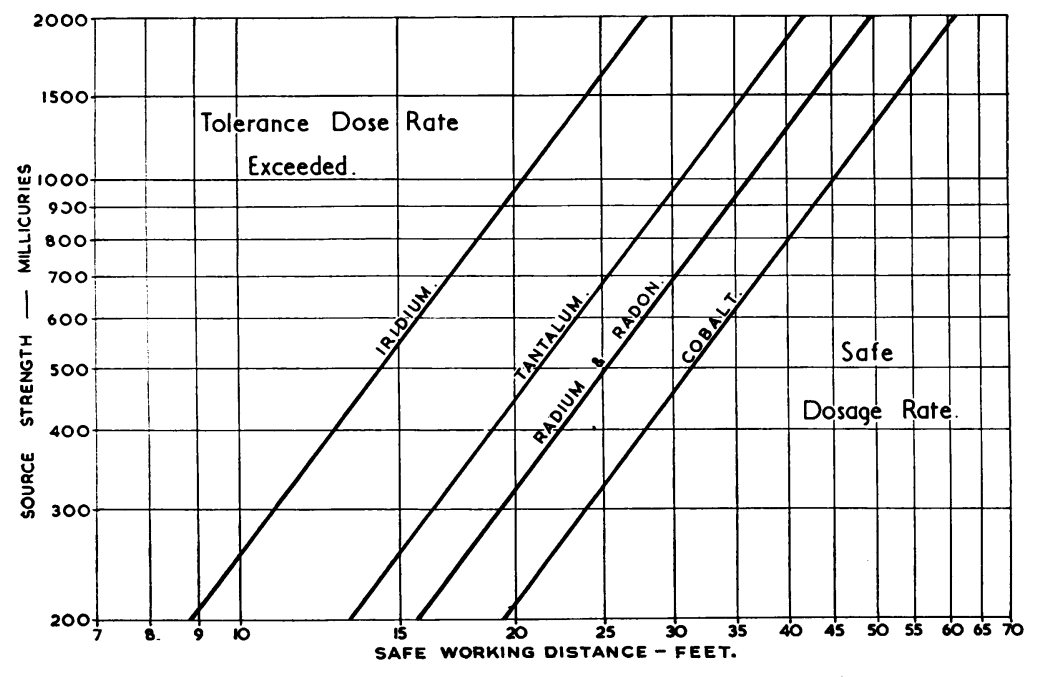

(DISTANCE from source to give tolerance dose rate)
FIG. A.-This is a chart for indicating the distances from various unshielded radioactive isotopes at which the dose-rate is equal to 7.5 milliröntgens per hour, i.e., the rate which, if continuously received over a 40-hour week, would eventually build up to the maximum permissible dose $(0.3$ röntgen). In the case of site radiography in factories, where the erection of permanent radiation shields was impracticable, this chart was therefore considered appropriate as a basis for determination of the distances from gamma-ray exposures at which some form of temporary barrier should be erected to prevent closer approach by unauthorized personnel.

Fig. A

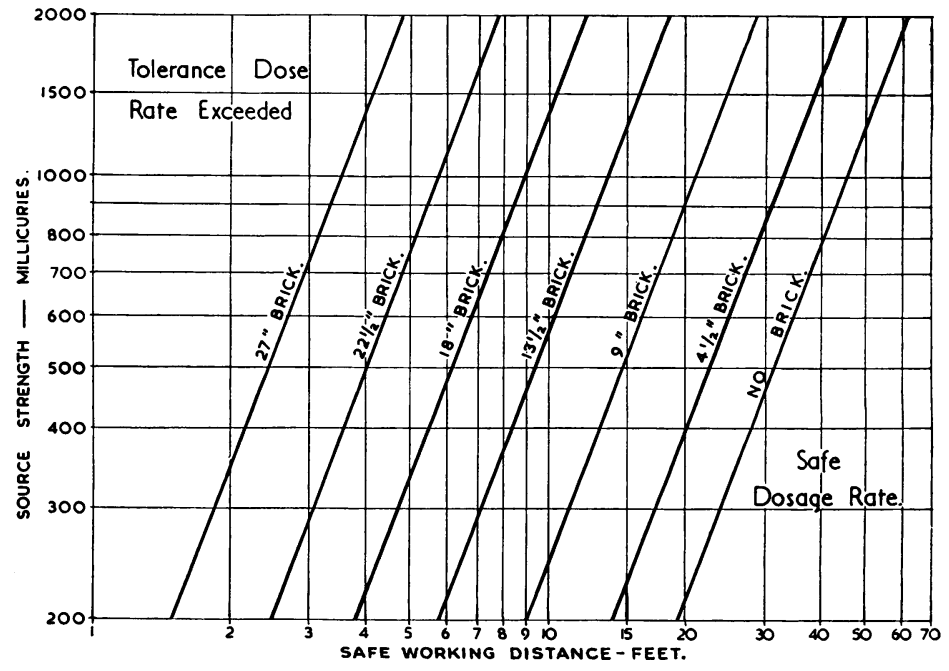

Fig. B.-This is a similar chart for determining the thickness of brickwork shields (in this case for brick of density $=1.9 \mathrm{~g} . / \mathrm{cc}$.), suggested as appropriate for surrounding radiographic exposures using ${ }^{60}$ cobalt, in cases where construction of a permanent exposure site was being considered.

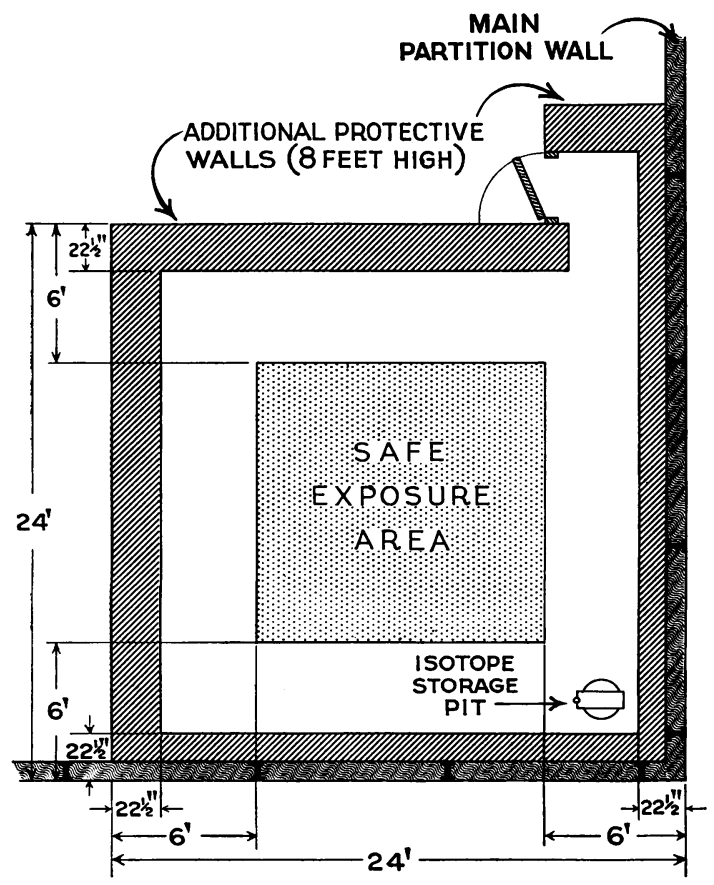

(DISTANCE FROM SOURCE to give tolerance dose ratie)

Fig. B

Fig. C.-This plan shows an exposure site of a type common in many steel foundries, the wall thickness being based upon the data given in Fig. B. Using a 1,000 mC source of ${ }^{60}$ cobalt, it would be seen that, provided exposure of the source was restricted to locations falling within the area marked out on the floor, the maximum permissible dose rate would never be exceeded at the outside surface of the brick wall. The enclosure would normally be open at the top to permit heavy castings being lifted in and out by overhead crane. The height of the roof of the shop would ensure that back-scatter from this source did not present a problem.

Fig. C 